\title{
Age structure, growth, mortality and yield-per-recruit of sergestid shrimp, Acetes indicus (Decapoda: Sergestidae) from the coastal waters of Malacca, Peninsular Malaysia
}

\begin{abstract}
Age structure, growth, mortality and yield-per-recruit of Acetes indicus were examined in the coastal waters of Malacca, Peninsular Malaysia between February 2005 and January 2006. Monthly length frequency data were analyzed using FiSAT software for estimating population parameters, including asymptotic length $(\mathrm{L} \propto)$, growth co-efficient $(\mathrm{K})$ and exploitation rate $(\mathrm{E})$ to assess the status of the stock. The $\mathrm{L} \propto$ and $\mathrm{K}$ for males were estimated at $29.40 \mathrm{~mm}$ and 1.70 year- 1 and for the females that were $42 \mathrm{~mm}$ and 1.20 years-1, respectively. The growth performance index $\left(\varphi^{\prime}\right)$ was calculated as 3.16 and 3.33 for males and females. The growth pattern of males and females showed positive allometric nature of growth $(b>3, p<0.05)$. The maximum life span (tmax) of males and females was 1.76 and 2.50 years, respectively. Total mortality $(Z)$ by length converted catch curve was estimated at 4.15 year- 1 for males and 3.50 year- 1 for females. The rate of natural mortality $(\mathrm{M})$ for males and females was calculated as 2.65 and 1.91 year-1 and the fishing mortality (F) was 1.50 and 1.59 year-1 for males and females, respectively. The recruitment pattern of A. indicus was continuous throughout the year with two major peaks. The exploitation rate (E) of males was 0.36 and that of females was 0.45 . The maximum allowable limit of exploitation (Emax) of males and females was 0.71 and 0.57 for the highest yield. The exploitation rates were less than the predicted Emax values of males and females. Thus, the stock of A. indicus was found to be under exploited in the investigated area.
\end{abstract}

Keyword: Acetes indicus, Age structure, Growth, Mortality 